\title{
Plasmacytoma of the pancreas: an unusual manifestation of multiple myeloma
}

Susan Swee Shan $\underline{H u e}^{1}$, MBBS, PhD, Rafay $\underline{\text { zhar }}^{1}$, MBBS, FRCPath

ABSTRACT Extramedullary plasmacytoma of the pancreas is a rare entity. Although this condition is uncommon, it should be considered in the differential diagnosis of solid mass in the pancreas, especially in patients with underlying multiple myeloma. We report a case of pancreatic plasmacytoma in a 56-year-old woman with newly diagnosed multiple myeloma. We highlight this rare manifestation of multiple myeloma among other better recognised presentations.

Keywords: multiple myeloma, pancreatic tumour, plasmacytoma

\section{INTRODUCTION}

An entity in the spectrum of plasma cell neoplasms, extramedullary plasmacytoma is characterised by localised monoclonal plasma cell proliferation that forms a solitary lesion outside the bone marrow. The disease can occur as a manifestation of advanced multiple myeloma with extramedullary involvement, or as a true solitary plasma cell tumour without any bone marrow plasmacytosis. ${ }^{(1-3)}$ We describe a rare case of pancreatic plasmacytoma diagnosed in a patient with newly discovered multiple myeloma.

\section{CASE REPORT}

A 56-year-old Chinese woman presented with right hypochondriac pain and unquantified weight loss over a period of one month. Her past medical history included diabetes mellitus and psoriasis. Radiologic evaluation revealed the presence of a solid mass measuring $3 \mathrm{~cm}$ in the midbody of the pancreas, which was suspicious for either a primary neuroendocrine tumour or pancreatic metastasis. An infiltrative, lytic, lower thoracic T9 vertebral lesion involving the right pedicle was noted, which was also thought to be metastatic. Serum cancer antigen 19-9 and chromogranin A were both within their respective normal limits. Biopsy of the vertebral bone lesion revealed the presence of a plasma cell myeloma, which corresponded with subsequent serological detection of monoclonal immunoglobulin (M protein). Haematological opinion was sought and the clinical impression was that the pancreatic mass was unlikely to be related to multiple myeloma. Fine needle aspiration of the pancreatic mass was then attempted on two separate occasions, which unfortunately did not yield any diagnostic material for evaluation. The pancreatic mass was subsequently excised for histological examination.

Macroscopically, the specimen consisted of distal pancreas and spleen. There was a well-circumscribed, solid mass in the body of the pancreas measuring $5 \mathrm{~cm} \times 3.5 \mathrm{~cm} \times 3.5 \mathrm{~cm}$. It had a homogeneous, tan-pink, firm-to-rubbery cut surface devoid of haemorrhage or necrosis. The patient's spleen was not involved.
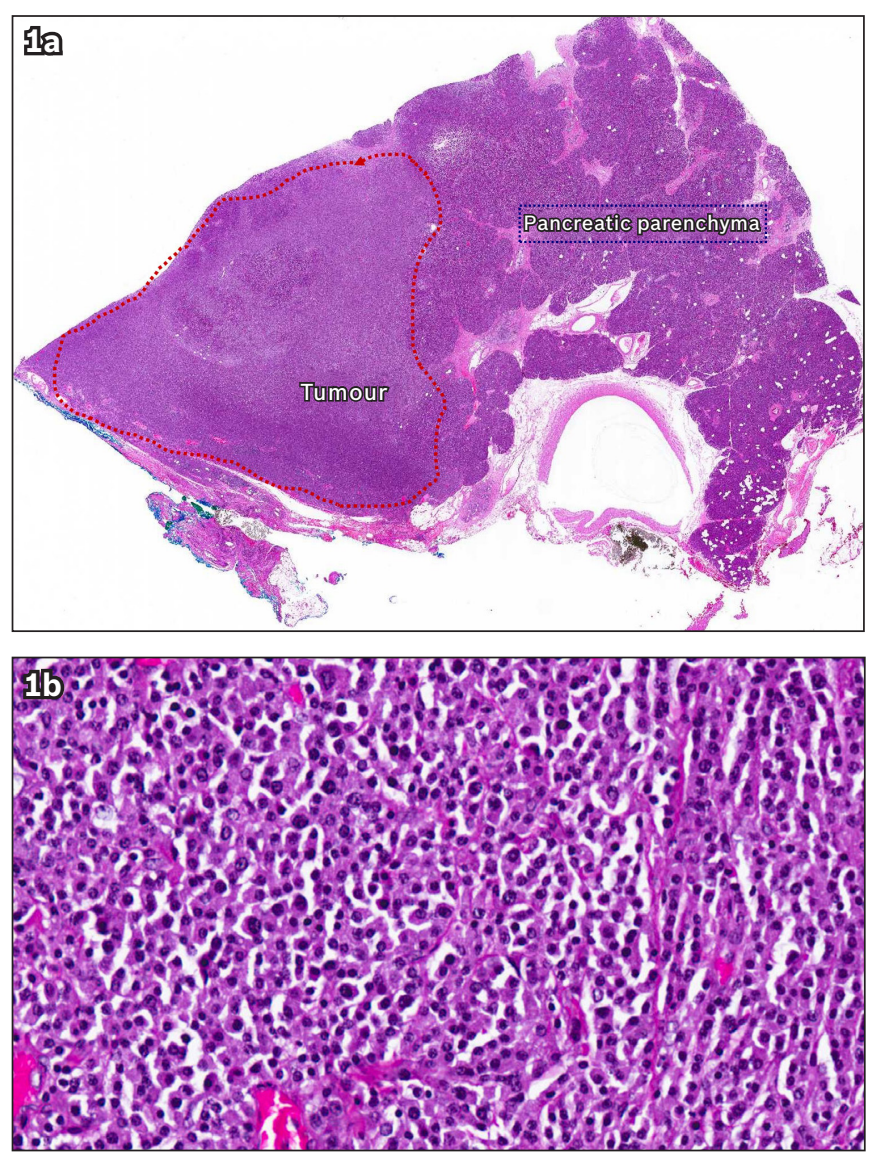

Fig. 1 Photomicrographs show (a) partial replacement of pancreatic parenchyma by an infiltrate of tumour cells (Haematoxylin \& eosin, $\times 2.5$ ); and (b) discohesive plasmacytoid cells with basophilic cytoplasm, eccentric nuclei and coarsely clumped chromatin (Haematoxylin \& eosin, $\times 200)$.

Histology showed sheet-like proliferation of predominantly immature plasma cells, with scattered mature plasma cells in the background (Fig. 1). On immunohistochemistry, the neoplastic cells were positive for CD138 (Fig. 2a), but negative for pan-cytokeratin marker, MNF116 (Fig. 2b). In situ hybridisation studies also demonstrated lambda light chain monotypia (Figs. 2c \& d). A diagnosis of plasmacytoma of the pancreas was thus rendered. 

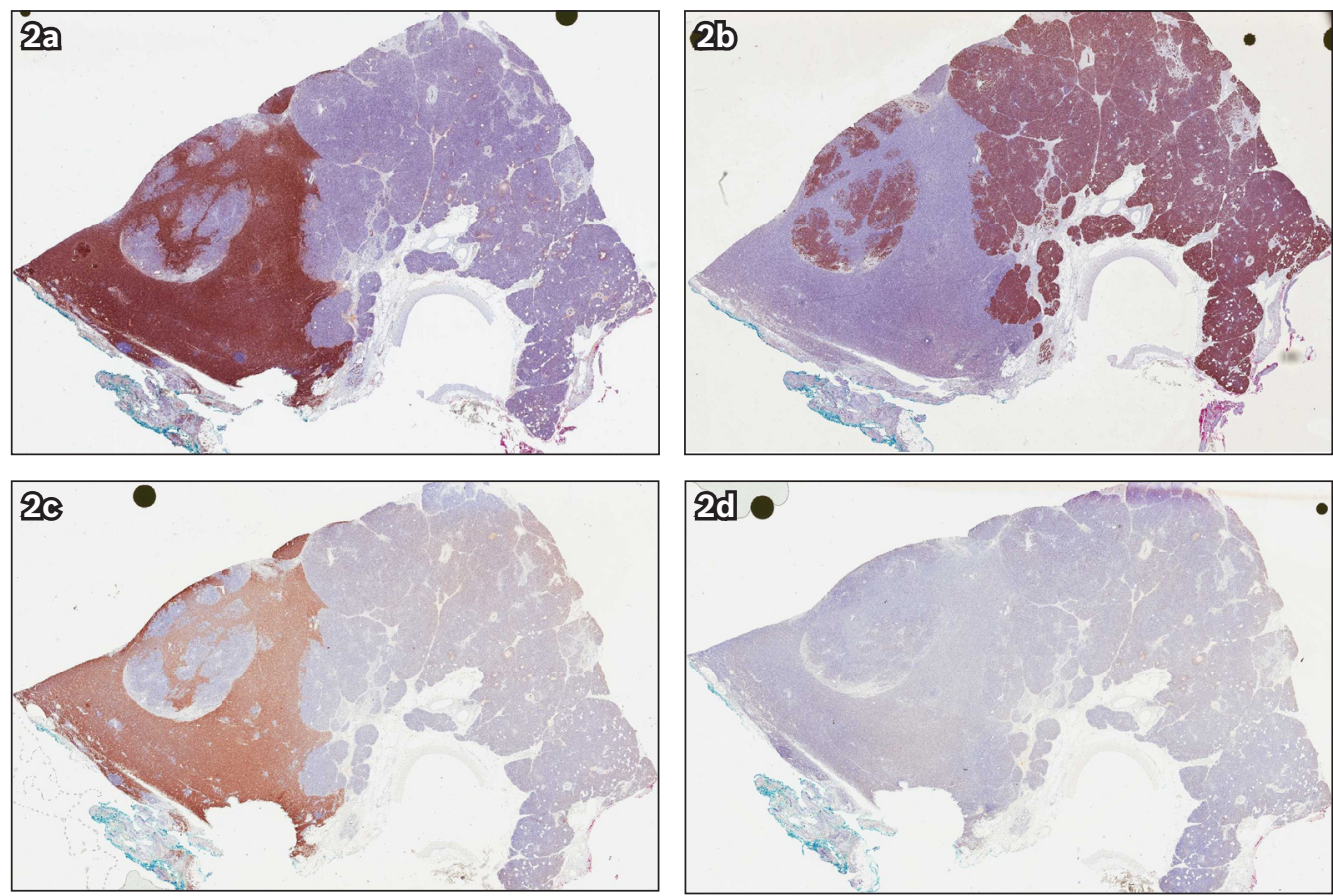

Fig. 2 Photomicrographs show tumour cells demonstrating (a) uniform and strong positivity for plasma cell marker CD138, in keeping with the diagnosis of myeloma; and (b) negative staining for pan-cytokeratin marker, MNF116. The monoclonal nature of the myeloma neoplasm is demonstrated by staining with (c) lambda and (d) kappa light chains (All immunoperoxidase stain, $\times 2.5$ ).

\section{DISCUSSION}

Plasma cell neoplasms and other related immunosecretory disorders are clonal proliferations of immunoglobulin-secreting, heavy chain class-switched, terminally differentiated B cells. These typically secrete a single homogenous immunoglobulin usually detectable as $M$ protein on serum or urine protein electrophoresis.(1) True plasma cell neoplasm includes multiple myeloma (also known as plasma cell myeloma), plasmacytoma and immunoglobulin deposition diseases, among others (Table I). Multiple myeloma is a bone marrow-based, multifocal plasma cell neoplasm associated with $\mathrm{M}$ protein in serum or urine. ${ }^{(1)}$ In most cases of multiple myeloma, there is disseminated marrow involvement (diffuse myelomatosis), although the disease can also present as solitary myeloma of the bone or involve other organs secondarily in the form of extramedullary plasmacytoma. ${ }^{(1-3)}$ The diagnosis of myeloma is made by a combination of clinical, morphologic, immunologic and radiographic information. The disease comprises 10\%-15\% of haematologic malignancies and clinically ranges from asymptomatic to highly aggressive disease. ${ }^{(1)}$

A plasmacytoma is a discrete but often solitary mass of neoplastic plasma cells that may occupy extramedullary sites. ${ }^{(4)}$ However, primary extramedullary plasmacytomas are uncommon and account for about $5 \%$ of all plasma cell neoplasms. ${ }^{(3-5)}$ They are commonly identified after the diagnosis of multiple myeloma, typically as a form of secondary involvement of extraskeletal organs. Rarely, there may be no evidence of bone marrow involvement (i.e. primary extramedullary plasmacytoma). ${ }^{(3)}$ Although most commonly found in the upper respiratory tract, extramedullary plasmacytoma also occurs in the gastrointestinal
Table I. World Health Organization's classification of plasma cell neoplasms, adapted from McKenna et al.(1)

\begin{tabular}{ll}
\hline $\begin{array}{l}\text { Types of plasma cell } \\
\text { neoplasms }\end{array}$ & Subtypes \\
\hline $\begin{array}{l}\text { Monoclonal gammopathy of } \\
\text { undetermined significance }\end{array}$ & - \\
Multiple myeloma & - Asymptomatic (smouldering) myeloma \\
& - Nonsecretory myeloma \\
& Plasma cell leukaemia \\
Plasmacytoma & - Solitary bone plasmacytoma \\
& Extraosseous (extramedullary) \\
Immunoglobulin deposition & plasmacytoma \\
diseases & Primary amyloidosis \\
& Systemic light and heavy chain \\
Osteosclerotic myeloma & deposition diseases \\
(POEMS syndrome) & \\
\hline
\end{tabular}

and genitourinary tracts, lungs, lymph nodes, skin and other locations. ${ }^{(6,7)}$ Reports of extramedullary plasmacytoma affecting the pancreas are sparse, and to date, to the best of our knowledge, just over 20 cases of pancreatic plasmacytoma have been reported in the literature. ${ }^{(2,8-11)}$ Most of these cases are associated with patients with underlying multiple myeloma. In our patient, the diagnosis of multiple myeloma was made before the diagnosis of plasmacytoma of the pancreas.

Typical presentation of extramedullary plasmacytoma of the pancreas includes jaundice and abdominal pain, which are often related to obstruction of the biliary tree. Described as either a focal, multilobular, solid mass with homogeneous intravenous contrast enhancement on computed tomography (CT), or a heterogeneous focal mass (hypoechoic relative to normal 
parenchyma) on ultrasonography, radiologic features ofextramedullary plasmacytoma are nonspecific. ${ }^{(12)}$ These nonspecific features commonly resemble typical findings in other pancreatic neoplasms, including neuroendocrine tumours, carcinoma, lymphoma and metastases. Although diagnosis is usually made by CT-guided percutaneous fine needle aspiration (FNA) biopsy, ${ }^{(13)}$ two attempts at FNA biopsy proved futile in obtaining diagnostic material in our case.

In conclusion, pancreatic plasmacytoma should be considered in the differential diagnosis of a patient with multiple myeloma and a pancreatic mass. A correct diagnosis obviates unnecessary surgery, as surgical procedures (other than distal pancreatectomy necessary for isolated pancreatic tail involvement) are not commonly performed due to the often systemic nature of the disease and its good response to local radiotherapy.

\section{REFERENCES}

1. McKenna RW, Kyle RA, Kuehl WM, et al. Plasma cell neoplasms. In: Swerdlow SH, Campo E, Harris NL, et al, eds. WHO Classifications of Tumours of Haematopoietic and Lymphoid Tissues, 4th ed. Lyon: IARC, 2008: 200-13.

2. Leake PA, Coard KC, Plummer JM. Extramedullary plasmacytoma of the pancreas as an uncommon cause of obstructive jaundice: a case report. J Med Case Rep 2009; 3:8785.

3. Kremer $M$, Ott $G$, Nathrath $M$, et al. Primary extramedullary plasmacytoma and multiple myeloma: phenotypic differences revealed by immunohistochemical analysis. J Pathol 2005; 205:92-101.

4. Nolan KD, Mone MC, Nelson EW. Plasma cell neoplasms: Review of disease progression and report of a new variant. Surg Oncol 2005; 14:85-90.

5. Hirata S, Yamaguchi K, Bandai S, et al. Secondary extramedullary plasmacytoma involving the pancreas. J Hepatobiliary Pancreat Surg 2002; 9:111-15.

6. C, Kau RJ, Dietzfelbinger $\mathrm{H}$, et al. Extramedullary plasmacytoma: tumor occurrence and therapeutic concepts. Cancer 1999; 85:2305-14.

7. Corwin J, Lindberg R. Solitary plasmacytoma of bone vs. extramedullary plasmacytoma and their relationship to multiple myeloma. Cancer 1979; 43:1007-13.

8. Wilson TE, Korobkin M, Francis IR. Pancreatic plasmacytoma: CT findings. AJR Am J Roentgenol 1989; 152:1227-8.

9. Fischer A, Suhrland MJ, Vogl SE. Myeloma of the head of the pancreas. A case report. Cancer 1991; 67:681-3.

10. Olson MC, Kalbhen CL, Posniak HV. Pancreatic plasmacytoma in a patient with multiple myeloma: CT and ultrasound findings. Abdom Imaging 1993; 18:323-4.

11. Hiller N, Goitein O, Ashkenazi YJ. Plasmacytoma of the pancreas. Isr Med Assoc J 2004; 6:704-5

12. Balliu E, Casas JD, Barluenga E, Guasch I. Multifocal involvement of the pancreas in multiple myeloma :sonographic, CT and MR imaging findings. AJR Am J Roentgenol 2003; 180:545-6.

13. Mitchell DG, Hill MC. Obstructive jaundice due to multiple myeloma of the pancreatic head: CT evaluation. J Comput Assist Tomogr 1985; 9:1118-9. 